STEEL FRAME DESIGN EXAMPLES 
By the same author

MORE STEEL FRAME DESIGN EXAMPLES 


\title{
STEEL FRAME DESIGN EXAMPLES
}

\author{
Ian Robb \\ M.Sc., C.Eng., M.I.Struct.E. \\ Lecturer in the Department of Civil Engineering \\ University of Salford \\ SI EDITION
}

THIRD EDITION

Palgrave Macmillan 
ISBN 978-1-349-81764-1 ISBN 978-1-349-81762-7 (eBook)

DOI 10.1007/978-1-349-81762-7

(C) Ian Robb 1961, 1965, 1972

Softcover reprint of the hardcover 1st edition 1972 978-0-333-02412-6

All rights reserved. No part of this publication may be reproduced or transmitted, in any form or by

any means, without permission

First published 1961

Second edition 1965

Third edition (SI) 1972

Published by

THE MACMILLAN PRESS LTD

London and Basingstoke

Associated companies in New York Toronto

Dublin Melbourne Johannesburg and Madras

ISBN 978-0-333-13404-7 


\section{Preface to Third Edition}

This book is primarily intended for students of structural steelwork design up to intermediate standard, and as an aid to young engineers gaining experience whilst engaged in professional practice.

It is assumed that the reader will have carried out some preliminary study in theory of structures and strength of materials which will enable him to appreciate the behaviour of simple structures, and steel as a material of construction.

The examples which follow are intended to give a broad outline of structural design using the medium of steel. This is accomplished in two ways, firstly by a thorough treatment of the design of structural elements, and secondly by demonstrating the arrangement of structural elements required to produce a safe and economical structure. Neither aspect can be viewed in isolation if the reader is to become a competent design engineer.

The diagrams and drawings illustrating the text should be viewed as typical details rather than as fully dimensioned working drawings. Students with no industrial experience may find it beneficial to make their own detailed drawings from the sketches given as a preliminary to the transition from the study of theory to the practice of design, a development that is not always easy to achieve. Drawings are an essential language of communication for the engineer and their importance should not be underestimated.

As far as is practicable, the provisions of BS 449 have been incorporated in the text. Students should not regard this specification in any other light than as a series of recommendations which form the basis for commercial design standards as well as professional practice.

The introduction of SI units into engineering is sufficient reason for a thorough revision of the text, but modifications in BS specifications regarding both design procedure and materials are equally important reasons for undertaking the task. In the ten years since the first edition was published the popularity of the triangulated framed structure has 
diminished and the popularity of the portal type frame has increased and for this reason the section of the text dealing with triangulated framed structures has been reduced. (For details of portal type framing, see 'More Steel Frame Design Examples' by the same author.) On the other hand, more detailed consideration has now been given to connections between structural members.

The author is indebted to the many students, colleagues and correspondents whose constructive comments have resulted in additional material as well as improved presentation being incorporated in the third edition.

I. RoBB 


\section{Contents}

List of Abbreviations $\quad$ ix

1 Preliminary Considerations of Design 1

1 The role of the engineer as a designer. 2 The role of the specification in design. 3 Design procedure. 4 Choice of sections when designing. 5 Relative costs of fabrication. 6 Relation of strength to weight in selecting sections. 7 Importance of load assessment. 8 Use of tabulated information.

\section{Elementary Design Definitions}

9 Relationship between load, stress, and strain. 10 Relationship between shear and bending. 11 Relationship between bending moment and moment of resistance. 12 Relationship between ultimate stress (or rupture stress), yield stress, and working stress. 13 Factor of safety. 14 Fatigue failure of material. 15 Brittle fracture. 16 Deflection of structures. 17 Geometrical properties of sections.

\section{Elements of Basic Design}

18 Beam design. 19 Struts. 20 Triangulated frameworks. 21 Design of tension members.

\section{Design of Multi-Storey Shop Premises}

22 Particulars of scheme. 23 Layout of steelwork. 24 Design of floor beams. 25 Effect of wind on building. 26 Design of columns (or stanchions). 27 Design of welded plate girder. 28 Design of welded connections. 29 Design of mass concrete foundation block. 30 Design of reinforced concrete foundation. 31 More about connections. 32 Typical strength calculations for connectors. 33 Typical strength calculations for connections. 
5 Design of $18 \mathrm{~m}$ Span Shed With Ridge-Type Roof Trusses

34 Particulars of scheme. 35 Layout of steelwork. 36 Effect of wind on building. 37 Roof purlins. 38 Design of roof trusses. 39 Design of side columns. 40 Design of mass concrete foundation to resist overturning. 41 Design of side and gable sheeting rails. 42 Design of gable steelwork. 43 Slenderness ratios of struts. 44 Note regarding design loads and choice of sections. 45 Design of rainwater gutters and pipes.

\section{Design of Braced Tower Supporting Water Tank}

46 Particulars of scheme. 47 Layout of steelwork. 48 Investigation of wind pressure. 49 Design of tank-supporting beams. 50 Design of tower members. 51 Design of foundation to resist uplift. 52 Check on estimated data. 53 Design of connections. 54 Provision of access to the tank. 55 Maintenance of the structure.

7 Some Aspects of Economical Design

56 Costs of fabrication. 57 Effect of layout upon design. 


\section{List of Abbreviations}

The following abbreviations have been used in the text and these follow the recommendations of BS 449, CP3 and CP114.

A Cross-sectional area

BS British Standard as issued by the British Standards Institution

$B$ or $b \quad$ Breadth

CP Code of Practice for buildings as issued by British Standards Institution

$D$ or $d \quad$ Depth

dia Diameter

E Young's modulus of elasticity (taken as $210 \mathrm{kN} / \mathrm{mm}^{2}$ for structural steel)

$\boldsymbol{e} \quad$ Lever arm

$f \quad$ Stress, in a general sense

$f_{c} \quad$ Calculated stress in axial compression

$f_{t} \quad$ Calculated stress in axial tension

$f_{b c} \quad$ Calculated compressive stress induced by bending

$f_{b t} \quad$ Calculated tensile stress induced by bending

$H \quad$ Horizontal reaction

I Moment of inertia (second moment of area)

$I_{x}, I_{y} \quad$ Moment of inertia measured about $x$ or $y$ axes

kg Kilogramme

$L \quad$ Overall length of member

$l \quad$ Effective length of member

$l_{x}, l_{y} \quad$ Effective length of member measured on the $x$ or $y$ axis of the member

$M \quad$ Bending moment

$\mathrm{m} \quad$ Metre; $\mathrm{m}^{2}$ square metre

$\mathrm{mm} \quad$ Millimetre; $\mathrm{mm}^{2}$ square millimetre; $\mathrm{m} / \mathrm{s}$ meter/second

$\mathrm{N} \quad$ Newton; $\mathrm{MN}$ meganewton; $\mathrm{kN}$ kilonewton; $\mathrm{kNm}$ kilonewton metre 
$p_{c}$

$p_{t}$

$p_{b c}$

$p_{b t}$

$p$

$q$

$R$

$r$

$r_{x}, r_{y}, r_{v}, r_{u}$

\section{$S 1, S 2, S 3$}

$T$

$t$

UB

$\mathrm{UC}$

$V, V_{s}$

$W$

$x$

$y$

$z$

\section{LIST OF ABBREVIATIONS}

Load in a general sense (used where $W$ would cause confusion)

Allowable stress in axial compression

Allowable stress in axial tension

Allowable compressive stress induced by bending

Allowable tensile stress induced by bending

Unit wind pressure

Dynamic wind pressure

Reaction to a system of loads

Radius of gyration

Radius of gyration measured about $x, y, v$ and $u$ axes respectively

Wind speed factors

Thickness of compression flange of a section

Thickness

Universal beam section

Universal column section

Basic wind speed and design wind speed respectively

Load or force

Major axis of a section

Minor axis of a section; also distance from an axis to a plane of investigation

Section modulus 